\title{
Costumbre y tradición: la cultura popular entre la rebeldía y el conservadurismo
}

\author{
NAZARENo Bravo \\ INCIHUSA-CONICET \\ Mendoza, Argentina
}

RESUMEN: El análisis de la cultura popular ba estado plagado de muchas simplificaciones, sobre todo en lo concerniente al tema de las costumbres. Bravo plantea que las costumbres y las tradiciones no son necesariamente conservadoras, como pretenden los abordajes simplistas.

ABSTRACT: The analysis of popular culture tends to be quite simplified, specifically on the theme of costumes. Bravo points that costumes and traditions are not necessarily conservative, as some simplistic approaches pretend.

El interés en el estudio de la cultura popular surge de la necesidad de comprender fenómenos sociales que incluyen —en su producción y/o práctica- a sectores subalternos de la sociedad, y que por diversas razones no fueron dimensionados en toda su riqueza desde el punto de vista científico. Así, numerosas manifestaciones expresivas o políticas populares fueron entendidas o bien como simples aceptaciones de un orden impuesto "desde arriba" o bien como prácticas revolucionarias en sí mismas, debido

Costumbre y trodiclón: la culturo popular entre la rebeldio y el conservodutiemo 
a su carácter proletario o, en términos más amplios, subalternos. Estas posiciones, aunque proporcionaron aportes concretos que ameritan ser reconocidos, no colaboraron - a nuestro entender- en la conformación de un cuadro más realista de la situación de aquellos sectores que no son dominantes.

Subyacen aquí, numerosos y necesarios debates teóricos sobre aspectos fundamentales a la hora de hablar de "cultura popular".

¿Qué incluyen los conceptos de cultura, costumbres o tradición? ¿Quiénes forman parte del pueblo? ¿Existe una cultura puramente popular? ¿Todo lo que hace el pueblo es popular?

Son estas algunas de las numerosas interrogantes que guían nuestra atención hacia este campo, al que consideramos parte fundamental del análisis sociológico a la hora de entender los procesos sociales que ocurrieron/ocurren en la sociedad. Nuestra intención no es la simple descripción de hechos o fenómenos “como cosas", sino más bien, su comprensión profunda como parte del análisis necesario, a la hora de desentrañar las formas y estrategias elegidas por los sujetos sociales para desenvolver su vida, expresarse y —en ciertos casos- transformar la sociedad; todo ello en un contexto en que actúan junto y en oposición a otros sujetos.

Rastrear el interés por lo popular nos obliga a recorrer un camino que se inicia en el siglo XVIII con los antecesores del romanticismo europeo, hasta llegar a los debates actuales que incluyen nociones de lo popular latinoamericano o nacional, pasando previamente por la crítica tanto de ciertas miradas antropológico-paternalistas hacia lo que hacen "los despojados", como -en el extremo opuesto- de sobrevaloraciones relativas al papel transformador de determinadas prácticas populares o de análisis deterministas producidos desde categorías marxistas.

El camino recorrido por el análisis de la cultura popular ha atravesado distintas etapas, en las que ha prevalecido una u otra mirada. En ese itinerario, el problema de la cultura popular surge hoy como un punto central de interés, sobre todo a la hora de comprender ciertos hechos que ocurren en la actualidad nacional y que afectan o interesan a los crecientes sectores subalternos de nuestra sociedad. De allí nuestra necesidad por vislumbrar su génesis, sus posibles antecedentes, lo que porta de novedad; en fin, por comprender el desarrollo y la capacidad de transformación que tienen las expresiones populares. 
El trabajo intenta hacer una aproximación a la definición de cultura popular, para luego rastrear las raíces del interés en la misma en la extensa transición hacia el capitalismo industrial en la Europa del siglo XVIII; en este marco analizaremos el ámbito de las costumbres - como espacio de reproducción y relectura de experiencias comunes-. Desde allí, guiaremos nuestra atención hacia el doble rol que la costumbre cumple como justificación de un orden establecido y/o como elemento de resistencia de las clases populares.

Profundizaremos este último aspecto, al situar los motines y revueltas ocurridos en Inglaterra en el siglo XVIII más allá de las explicaciones simplistas que ven en ellos sólo "reacciones al hambre". Finalmente, ingresaremos al debate sobre la tradición y la necesidad de analizar este concepto en realidades concretas, para evitar análisis desprevenidos, que sólo encuentran en ella aspectos conservadores.

En definitiva, lo que intentamos analizar es el campo de la cultura, como espacio dinámico de confrontación y negociación entre sectores sociales, que pugnan por imponer su visión al resto. Esto nos obliga a problematizar el concepto de cultura como simple reflejo de la estructura económica y encontrar en ella, elementos que son utilizados de forma diferente, según situaciones, tiempo y actores sociales.

\section{La compleja definición de la cultura popular}

Existen no pocas dificultades a la hora de hacer confluir dos conceptos tan complejos como cultura y popular.

Por un lado, subyace la idea de que una cultura popular incluye una "concepción del mundo y de la vida contrapuesta a las concepciones oficiales y a la de los sectores cultos ${ }^{1}$, es decir, una cultura propia, del pueblo, que sirve a sus intereses, soluciona sus necesidades y que se diferencia claramente de los sectores dominantes de la sociedad.

Sin embargo no problematizar esta idea puede guiarnos por el camino del determinismo hacia la concepción de la cultura popular como espacio autónomo de una clase social o, en el mejor de los casos, de los "grupos subalternos". Ello paraliza y empobrece un concepto por demás rico en posibilidades.

Puede ser útil el aporte de Stuart Hall, que define la cultura popular como un conjunto de

"formas y actividades cuyas raices [están] en las condiciones 
sociales y materiales de determinadas clases, que bayan quedado incorporadas a tradiciones y prácticas populares. Lo que aqui define la cultura popular, son las relaciones en tensión continua (relación, influencia, antagonismo) con la cultura dominante. Es un concepto de la cultura que está polarizado alrededor de esta dialéctica cultural. Trata el dominio de las formas y actividades culturales como un campo que cambia constantemente. Luego examina las relaciones que de modo constante estructuran este campo en formaciones dominantes $y$ subordinadas. Examina el proceso mediante el cual se articulan relaciones de dominación y subordinación. Las trata como proceso: el proceso por medio del cual algunas cosas se prefieren activamente con el fin de poder destronar otras. Tiene en su centro las cambiantes $y$ desiguales relaciones de fuerza que definen el campo de la cultura; esto es, la cuestión de la lucha cultural y sus muiltiples formas. Su foco principal de atencion es la relación entre cultura y cuestiones de hegemonia"s.

Queda a la vista que, si se toma en cuenta esta última definición, casi todas las formas culturales serán contradictorias en sí mismas, compuestas por elementos antagónicos e inestables, y que lo que importa no son los objetos intrínsecos o fijados históricamente de la cultura, sino el estado de juego en las relaciones culturales: lo que cuenta es, por tanto, la lucha de clases en el espacio de la cultura y por la apropiación y re-significación de la cultura.

En definitiva, la cultura popular no puede ser simplemente "ubicada" en todo lo que produzcan, utilicen o sientan las clases subalternas. Esto nos llevaría a desconocer las relaciones, influencias, imposiciones, confrontaciones y alianzas que se producen entre sectores sociales "opuestos" o, con otras palabras, la lucha de clases en el campo de la cultura.

Por otro lado, este carácter mediatizado y complejo del concepto, no debería llevarnos a desconocer que la cultura popular existe. Sin lugar a dudas, hay prácticas y objetos que son propios de las clases subalternas, responden a sus necesidades y son reconfigurados con el paso del tiempo y según situaciones determinadas. Su característica - más allá de las distintas situaciones- estaría dada por su carácter de oposición (oposición a una cultura de élite), lo que nos lleva a reconocer que la que se opone no es únicamente una clase social - "el proletariado"-, sino todas aquellas 
que no son dominantes y que, según la situación, comparten ámbitos comunes de producción material y simbólica.

En resumen: la cultura popular no es un área estática que podamos encontrar en todo lo que hace "el proletariado" - concepto apropiado para una sociedad industrial-o la clase subalterna, entendida como una entidad dada y con límites - sociales e ideológicos - claramente definidos. Por el contrario, será más conveniente destacar el carácter histórico del concepto de clase y hablar de "clases subalternas" (opuestas a "clases dominantes") y diferenciarlas en cada momento histórico, sin intentar proletarizar a toda clase subalterna de cualquier tiempo y lugar. Así, al hablar de cultura popular, nos encontramos ante un campo de lucha en el que diversos intereses y prácticas se contraponen y que por lo tanto incluirá aspectos "propios" y "ajenos", aunque reconfigurados y releídos desde diferentes visiones y situaciones concretas.

Los debates sobre la cultura popular no son nuevos y adquieren especial importancia cuando se los contextualiza como una problemática "moderna" que acompaña el surgimiento del capitalismo.

\section{La dinámica cultural en la transición al capitalismo}

El interés sobre la cultura popular tiene importantes antecedentes en el estudio de las transformaciones culturales acaecidas durante la extensa etapa de transición desde las formas de organización propias de un feudalismo tardío (sociedad estamental) hacia el capitalismo agrario y, luego, en el lento proceso de formación y evolución del capitalismo industrial en Europa (sociedad de clases).

La larga duración de esta transición -que se inicia a comienzos del siglo XVI y alcanza puntos clave entre mediados del XVIII y la década del 40 del XIX-, impide determinar un corte histórico preciso, en el que cambien decisivamente las formas de percibir y valorar la realidad y acaezcan, de manera inequívoca y repentina, las mutaciones en el ámbito económico, político y social, que caracterizarían, en etapas posteriores, a una sociedad capitalista industrial. Por el contrario,

"Francia, país al que se tiene como ejemplo central de una revolución burguesa [...] resulta haber seguido una vía particular que lleva a la práctica eliminación de la nobleza antigua, mientras que son más frecuentes procesos como la 'via inglesa' o vía prusiana" de evolución desde el Antiguo Régimen, en las que las que la creación de una nueva clase emengente no pasa por la desaparición de la aristocracia. Los señores territoriales 
eran ya en el siglo XVIII en su mayoria propietarios capitalistas, no señores feudales ${ }^{* 3}$.

Es decir, la complejidad y diversidad de las transformaciones en el ámbito social y político exigen una consideración respetuosa y atenta de las especificidades, la que no puede agotarse en la rápida categorización de una formación social como "feudal" o "capitalista"4.

Los procesos de transformación social en el tránsito a las sociedades capitalistas plantean dificultades y limitaciones para su comprensión unívoca a partir del concepto de "revoluciones burguesas". Por una parte, ello implicaría dar por sentada una formación consolidada y plenamente consciente de los intereses de la clase burguesa, de su papel en la configuración de una nueva sociedad y de su programa; por otra, inducirá a pensar en un paso inmediato de una etapa a la otra. En definitiva, parece más conveniente hablar de revoluciones "liberales", como un concepto más amplio de las transformaciones y de sus protagonistas.

Esta perspectiva permite ponderar, en la larga transición de la que venimos hablando, numerosas situaciones históricas que, tanto en sus expresiones políticas como sociales, conservaban rasgos de fondo de las antiguas sociedades agrarias, mientras se ajustaban al nuevo y todavía inestable modo de organización.

Así, la configuración capitalista completamente definida, alcanzada en el s. XDX —entendida como "la plena implementación del sistema de propiedad privada ligada al mercado y las formas políticas representativas, aunque enormemente restringidas por el sufragio censitario"s, convive necesariamente con modos, visiones y prácticas que luchan por su permanencia en el nuevo escenario. Esto último es de vital interés en nuestro análisis, ya que nos ubica en una problemática específica, referida a los "distintos tiempos" de cambio que pueden observarse en los aspectos económicos y/o institucionales respecto de las transformaciones en la cultura.

La formación y consolidación del Estado moderno (capitalista), surgido de las grandes revoluciones del siglo XVIII, tiene antecedentes que deben ser buscados en las reestructuraciones que acompañaron -cuando no apoyaron- las propias monarquías absolutas en sus formas "ilustradas". Estas nuevas monarquías surgieron en el siglo XVI como producto de la superación de la fragmentación política del mundo feudal y representaron la creación de nuevas estructuras de Estado, su fortalecimiento en una 
gran organización burocrática que mantuvo una precisa y eficaz dialéctica con la expansión del sistema capitalista. Sin embargo, esta nueva forma de gobierno encontró limitaciones para desarrollar un sistema más eficiente, acorde con la necesidad de centralización del poder y del establecimiento de la dependencia administrativa de instituciones mejor organizadas, que permitiesen el desarrollo económico sin trabas propias de la etapa anterior: aduanas interiores, siervos de la gleba, privilegios de señores feudales, etc.

Si bien el absolutismo ilustrado auspició el desarrollo de la burguesía, sobre todo en su aspecto comercial,

...al mismo tiempo, y en flagrante contradicción con lo anterior frenó el surgimiento de la burguesía con el mantenimiento de estructuras sociales tradicionales y el control de las actividades productivas. Efectivamente, tanto si consideramos el periodo clásico del absolutismo monárquico, el de Luis XIV, como el del absolutismo ilustrado, de Federico II o Catalina II, comprobamos que, por detrás de la fachada de una autoridad teóricamente absoluta, el privilegio nobiliario está a salvo, la explotación señorial se mantiene $y$, por un tiempo, la sociedad aristocrática está estabilizada ${ }^{6}$.

Vale recalcar que no se trata, en modo alguno, de un fenómeno temprano (tal vez la excepción sea Gran Bretaña, que ya para el siglo XVIII posee instituciones parlamentarias), sino que, su establecimiento definitivo no es anterior a la década de 1830.

De aquí que este gran movimiento de refundación institucional se complementara con la emergente idea de Nación, (opuesta a la de Corona o Reino y a su origen divino) que marca el cambio de las concepciones legales y "transforma" a los súbditos en ciudadanos. Si bien, estos últimos no serán todos los habitantes de la Nación - por tanto podría hablarse de una ciudadanía restringida - es notoria la diferencia con etapas anteriores.

La creación del Estado-nación contemporáneo responde a diversos estímulos - el cambio económico, la necesidad de ingresos y la coerción para conseguirlos, las presiones externas y las nuevas ideologías-y puede ser entendida como la "suma dinámica de coerción y capital"'. En efecto, según la tesis de Anthony Giddens, el Estado-nación industrial es, en el fondo, el origen de un pacto entre elites, en virtud del cual el poder 
político y el económico van a funcionar en esfera diferenciadas y coordinadas. La coerción económica y el poder de libre mercado, pasará a la órbita de los capitalistas. El ejercicio del poder político, basado en el no-intervencionismo en la economía, en el sufragio controlado y en el orden burgués, quedará en manos de élites políticas que detentan el monopolio de la violencia ${ }^{8}$.

Nuevas dificultades surgen cuando intentamos examinar la emergencia y la expansión de la sociedad de clases, así como su interrelación como factor desencadenante o como resultado de una "revolución burguesa", que habría destruido las formas antiguas de las sociedades estamentales. Al igual que las nuevas formas de organización económica y el Estado, su aparición en escena no puede determinarse con absoluta claridad. Sin embargo, parece contribuir al análisis su comprensión como proceso que se va desarrollando paulatinamente ( $y$ que por otro lado, no ha dejado de desarrollarse), directamente relacionado con los cambios económicos y políticos.

La compleja definición de lo que consideramos "clases", y en particular, de la nueva clase dominante, resulta importante a la hora de introducirnos en la problemática de la hegemonía que ejercería una clase sobre las demás, en lo económico y (por tanto) en lo ideológico.

Puede ser interesante al respecto, retomar el análisis que realiza Edward Thompson -integrante destacado de la Escuela de Estudios Culturalesrelativo a la situación en Inglaterra del siglo XVIII. El autor, remarca que al no existir una formación industrial establecida, no podría hablarse de lucha de clases, ya que las clases -obrera y burguesa- como tales, no estarían totalmente conformadas. Sin embargo, advierte sobre lo erróneo de considerar que esto suponga la inexistencia de enfrentamientos y luchas permanentes, por lo que propone hablar de protoconfilicto.

"Por supuesto, en siglo XVIII a nadie se le bubiera ocurrido decir que la suya era una "sociedad de una sola clase". Estaban los gobernantes y los gobernados, la gente alta y la gente baja, las personas de recursos y patrimonio independiente $y$ las disolutas y levantiscas. Entre los dos extremos, donde deberian baber estado las clases profesionales y medias las relaciones de clientela y dependencia eran tan fuertes, que, al menos basta la década de 1760, parece que estos grupos se desviaron poco de las polaridades esenciales [...] Pero semejante polarización de las 
relaciones entre las clases no priva por esa razón a la plebe de toda existencia política. Una plebe no es, quizá, una clase trabajadora. La plebe puede carecer de la consistencia de una autodefinición, de conciencia, de claridad de objetivos, de la estructuración de la organización de clase. Pero la presencia política de la plebe o 'chusma' o 'multitud' es manifiesta y afectó a la alta politica en multitud de ocasiones críticas (motines, agitaciones contra impuestos, explosiones patrióticas chauvinistas, etc)" .

Lo que se intenta marcar aquí, es que el paso del feudalismo al capitalismo, no se produjo mecánicamente, ni al mismo tiempo en los países europeos. Tanto las revoluciones liberales como el surgimiento de los Estado-Nación y la consolidación de la burguesía como clase dominante, deben comprenderse como fenómenos que se desarrollan a partir del siglo XVI, y que van adquiriendo características particulares en cada país. De esta manera podrá advertirse que este largo proceso no pudo barrer, de una vez para siempre, lo que hemos denominado "cultura". Por el contrario, será este uno de los escenarios donde las transformaciones encontraron más resistencia y donde es posible observar cómo los nuevos valores, que conllevan las transformaciones, conviven en algunas ocasiones y no siempre en forma armónica, con las pautas culturales propias de las clases subalternas. Esto incluye tradiciones, creencias y estilos de vida de estos sectores, que fueron la base de las formas de vida comunitaria anteriores a la etapa capitalista.

"El capital tenía interés en la cultura de las clases populares porque la constitución de todo un orden social nuevo alrededor del capital requería un proceso más o menos continuo, pero intermitente, de reeducación en el sentido más amplio de la palabra. Y en la tradición popular estaba uno de los principales focos de oposición a las formas por medio de las cuales se pretendia llevar a término esta 'reformación' del pueblo"10.

\subsection{La cultura popular: lugar de oposición y resistencia}

La posibilidad de reflexionar fructíferamente sobre las resistencias en el campo cultural depende, en gran medida, de tomar en cuenta las pautas culturales de las clases subalternas como válidas y significativas para sus portadores. En este sentido, es fundamental el aporte de autores que, contra la visión predominante de su época, cuestionaron la existencia 
de una única cultura (que podemos identificar como la dominante) y prestaron atención - confiriéndole un estatuto particular-a otras formas culturales, propias de las clases bajas o de los países atrasados.

En este sentido, resulta importante destacar algunas consideraciones de Johann von Herder, quien, contra la idea ilustrada de una razón única y universal, puso énfasis en las especificidades de los caracteres nacionales. Como es sabido, en su obra: Ideas sobre la filosofía de la historia de la bumanidad 1784-1791 ${ }^{11}$, Herder cuestionaba el supuesto de las Historia universal, según el cual la "civilización" o la "cultura" —el autodesarrollo histórico de la humanidad- era lo que hoy llamaríamos un proceso unilineal, conducente al punto elevado y dominante de la cultura europea del siglo XVIII. Williams interpreta el pensamiento de Herder en lo relativo al aspecto señalado como un ataque a la subyugación y dominación europeas de los cuatro rincones del globo ${ }^{12}$.

La de Herder no sería una crítica antiliberal, sino un intento de ajustar la doctrina liberal a la variedad de culturas nacionales. Por ello proponía hablar de "culturas" en plural: las culturas específicas y variables de diferentes naciones y períodos, pero también las culturas específicas y variables de los grupos sociales y económicos dentro de una misma nación. Existe en este sentido, una manifiesta oposición a la noción ilustrada de la cultura del pueblo -definición negativa que incluye supersticiones, ignorancia y turbulencia-, que abre la posibilidad al amplio desarrollo de formas culturales alternativas respecto de la "civilización" ortodoxa y dominante, así como a la revalorización de "lo popular" como "espacio de creatividad cultural". Por ello Herder es considerado un antecesor del movimiento filosófico y literario romántico (siglo $\mathrm{XDX}$ ), que a partir de su crítica a la ilustración, recuperó las viejas tradiciones medievales y sirvió como base identitaria de las nacientes nacionalidades europeas y de los Estados independientes americanos.

\section{"La posición romántica bace progresar definitivamente la idea de que existiera, más allá de la cultura oficial y begemónica, otra cultura. La noción romántica del 'pueblo', cuya utilización conceptual es boy refutada, fue entonces un instrumento positivo para el ensanchamiento del borizonte bistórico y de la concepción bumana"13.}

Esta valorización de lo popular y su reconocimiento como espacio de creación cultural, permiten comprender más acabadamente el 
enfrentamiento constante, en la etapa de consolidación de la sociedad capitalista, de los sectores subaltemos con lo que podríamos llamar nueva cultura y posteriormente cultura oficial (del Estado-Nación). Es una lucha entre dos modelos distintos de comprender el mundo, la vida en sociedad y lo cotidiano. Al pueblo le cuesta entrar en la lógica de mercado que propone la nueva organización capitalista de la sociedad, que barre con lazos comunitarios de larga data, en nombre de la libertad de comercio. Por ello, de una u otra forma, intentará aferrarse a costumbres, creencias y prácticas -es decir a su cultura-, a modo de dique de contención, ante una cultura que se le presenta extraña y que por cierto, ha logrado sentar bases más firmes en ámbitos como el político-institucional y el económico.

Vale aclarar que, el ámbito de la cultura popular al que podríamos denominar de las "costumbres", no debería entenderse como homogéneo y uniforme. Por el contrario, como afirma Thompson se trata de un "campo de cambio y contienda, una palestra en la que intereses opuestos hacen reclamaciones contrarias"14. Tal vez la idea de "choque y diálogo" planteada por Carlo Ginzbourg para describir el pensamiento popular, resulte apropiada en este sentido ${ }^{15}$. Queremos decir que el ámbito de las costumbres que presenta resistencia, no es un todo compacto, detenido en el tiempo; por el contrario es resultado de un proceso de luchas, que se mantiene en constante transformación. Sin embargo, existe un anclaje en procesos históricos y sociales comunes - tanto en su sentido de "oposición a la nobleza" como en el de "algo compartido"16_, que lo hacen establecerse como "tradicionales" para una comunidad, aunque muchas de estas costumbres, visiones y prácticas en común difieran, en tiempo y origen.

Por tanto, sería incorrecto suponer que esta cultura popular que se resiste, es resultado de procesos sociales ocurridos únicamente en, desde y para el campo popular. Retomamos la idea de campo de intercambio casi siempre desigual-, en el que sectores populares se aferran a costumbres que pueden haber sido en su origen, imposiciones patricias (o simplemente no-populares), pero que son aprehendidas y practicadas desde cosmovisiones propias y a las que además, se apela en determinado momento como forma de defensa. Para Thompson "cultura es un fondo de recursos diversos, donde hay tráfico entre lo escrito y lo oral, lo superior y lo inferior (subordinado), el pueblo y la metrópoli"17. 
De esta manera se podrá vislumbrar la importancia que la cultura popular tuvo como forma de resistencia (a la economía política de mercado) y oposición, ante los intentos de imponer nuevos valores (capitalistas). Este hecho es muchas veces vinculado con formas tradicionales de vida, que proceden del pasado, por lo que no es difícil establecer un falso tándem "tradición-conservadurismo". Pues, como señala Stuart Hall cuando se refiere al avance de la nueva cultura

lo que estamos viendo en realidad es la destrucción activa de determinadas maneras de vivir y su transformación en algo nuevo. 'Cambio cultural' es un eufemismo cortés que disimula el proceso en virtud del cual algunas formas y prácticas culturales son desplazadas del centro de la vida popular, marginadas activamente para que otras puedan ocupar su lugar"18.

Así, la disociación entre cultura patricia y plebeya y su articulación con la lucha en el campo cultural entre costumbres, ritos y creencias aceptadas por el Estado-nación y los grupos del pueblo que mantienen las propias por obra de la tradición ${ }^{19}$, surge como un interesante punto de análisis.

Es durante el siglo XVIII, donde encontramos ejemplos claros de "cultura tradicional rebelde". Son formas de resistencia a las racionalizaciones e innovaciones políticas y económicas, que encubren con mayor o menor suerte, situaciones de explotación y expropiación de derechos y de usufructos acostumbrados, así como también la alteración violenta de pautas de trabajo y ocio valiosas ${ }^{20}$. Estos posicionamientos de sujetos sociales que resisten incluyen formas particulares de control social -sanciones, condenas, premios y castigos- que se hacen efectivas en prácticas comunitarias. Este es el tema del siguiente apartado.

\subsection{Motines y revueltas como formas de resistencia}

Sin lugar a dudas, en este terreno se hace necesario recurrir nuevamente a los aportes realizados por Thompson, y en particular a sus análisis de prácticas y formas de protesta propias de los sectores subalternos de la Inglaterra del siglo XVIII y principios del XIX.

En el estudio de los motines producidos en Inglaterra a lo largo del siglo XVIII, Thompson evita la explicación lineal y monocausal de la "reacción ante la miseria y el hambre" ${ }^{21}$. Sostiene que en estas acciones de masas es posible detectar nociones legitimizantes, es decir, que aquellos que participaban de estas revueltas creían estar defendiendo derechos o 
costumbres tradicionales, que contaban con el amplio consenso de la comunidad. En ocasiones este consenso popular era afirmado por una cierta tolerancia por parte de las autoridades, pero en la mayoría de los casos, el consenso era tan marcado y enérgico que anulaba las motivaciones de temor o respeto ${ }^{22}$.

Surge aquí, la noción de "economía moral de la plebe" como la idea tradicional de las normas y obligaciones sociales, de las funciones económicas propias de los distintos sectores dentro de la comunidad. La violación o intento de incumplir dichas pautas podía desembocar, en numerosas ocasiones, en acciones directas.

Aunque esta «economía moral» no puede ser descrita como estrictamente "política», tampoco puede, no obstante, definirse como apolítica, puesto que supone nociones del bien público categórica y apasionadamente sostenidas, que, ciertamente, encontraban algún apoyo en la tradición paternalista de las autoridades; nociones de las que el pueblo, a su vez, se hacía eco tan estrepitosamente que las autoridades eran, en cierta medida, sus prisioneras. De aquí que esta economía moral tiñese con carácter muy general el gobierno y el pensamiento del s. XVIII, en vez de interferir únicamente en momentos de disturbio. La palabra «motín» es muy corta para abarcar todo eso ${ }^{23}$.

El desarrollo del libre comercio capitalista, efectuado en largas y desiguales etapas de transición, supuso - además de una nueva organización de la producción- la difusión de prácticas y valores opuestos en la mayoría de los casos, a aquella "economía moral" y en ruptura con los hábitos de consumo. Tales valores y prácticas se hacían evidentes en situaciones concretas de la vida cotidiana, como la obtención de alimentos en el mercado, por ejemplo. Así, la aparición de intermediarios entre el productor de harina y el público, las "trampas" para rebajar la calidad de la harina, la suba de precios, los cambios en las medidas de pesaje y sobre todo- la prioridad del mercado externo sobre la propia comunidad, fueron el contexto de la fuerte oposición popular que en ocasiones culminó en motines.

Es de destacar que estos modelos de protesta, reproducen en gran parte, las medidas de emergencia adoptadas en tiempos de escasez entre los años 1580 y 1630 y que llegaron a ser codificadas en el Book of Orders en 1630, compendio de derechos y deberes sociales que consideraba el precepto moral y el ejemplo como una parte integral de las medidas de emergencia ${ }^{24}$.

Costumbre y hodiclón: la culturo popular entre la rebeldia y el conservaduilamo 
La mirada de Thompson sobre el pasado pone en evidencia que prácticas y valores que hoy nos parecen "naturales" (como la orientación del comerciante hacia la consecución de la mayor ganancia posible), no siempre lo fueron y que inclusive tuvieron que soportar la resistencia de quienes se oponían desde otros valores; que eran percibido por ellos precisamente como "naturales".

El avance de la nueva economía política de libre mercado supuso también el desmoronamiento de la antigua economía moral de aprovisionamiento. A partir de comienzos del siglo XIX lo único que quedaba del "sistema paternalista" era la caridad. ${ }^{25}$ De este modo, el avance de la racionalización económica daba por tierra con las formas de organización social establecidas, que tenía en el paternalismo uno de sus ejes fundamentales. Esta fase de transición suponía, además, profundos cambios en la relación entre sectores de la sociedad: la equilibrada subordinación de la plebe ante el dominio patricio se transformaba paulatinamente, y no sin dificultad, en "negociación" entre "hombres libres" (proletarios y burgueses). Ello implicaba la aparición en escena de nuevos -o al menos renovados- conflictos, formas de trabajo y de disciplinamiento.

La economía moral de la muchedumbre tardó más tiempo en morir que el contexto que le dio sentido: fue recogida en los primeros molinos harineros cooperativos, por algunos de los socialistas de Owen y subsistió durante años en algún fondo de las entrañas de la Sociedad Cooperativa Mayorista (una de las primeras experiencias cooperativistas de la historia, que tuvo lugar en Rochdale en 1844). Pero finalmente sucumbió a la nueva dinámica de los tiempos, y Thompson llama la atención sobre el modo en que esa extinción ha dejado sus huellas en la interpretación histórica posterior:

"Un sintoma de su final desaparición es que bayamos podido aceptar durante tanto tiempo un cuadro abreviado $y$ "economista" del motin de subsistencia, como respuesta directa, espasmódica e irracional al hambre; un cuadro que es en si mismo un producto de la economía política que redujo las reciprocidades humanas al nexo salarial ${ }^{226}$.

Abordar la problemática de la tradición, como forma de resistencia a las nuevas pautas económico-sociales, pero sin descuidar la defensa de valores establecidos que ello implica, surge como un desafío para el análisis de los fenómenos culturales e identitarios de sujetos colectivos. 


\subsection{La tradición: iresistencia o conservadurismo?}

Nos introduciremos en una problemática tan compleja como interesante, a la hora de analizar las características culturales de un pueblo: la tradición.

Si bien por un lado, el aferrarse a la tradición ha servido como instrumento de resistencia de las clases subaltemas frente al avance de los sectores dominantes; por otro, las clases dominantes (especialmente los sectores conservadores) hacen una utilización de la tradición, como forma de condicionar la capacidad de aprehensión de la realidad social, al legitimar y naturalizar un orden establecido.

Esto ocurre porque el concepto de tradición puede denotar significaciones diferentes y hasta contradictorias en algún aspecto, abarcando un extenso arco, que va desde su comprensión como "transmisión de conocimiento" hasta la que la ve como "comunicación de una doctrina". En el primer caso, se encuentran aquellos conocimientos teóricos y prácticos necesarios para vivir (comprender y resolver situaciones diversas) en sociedad. Aquí podríamos incluir experiencias y valores del pueblo, es decir, aquello propio o que ha sido vivido como propio por las clases subalternas en tiempos pasados y que en la actualidad sirve como fuente de información para su vida cotidiana.

Por otro lado, considerar la tradición como "comunicación de una doctrina", supone características diferentes a las antes mencionadas, que se vinculan, más bien, con ideales y valores impuestos por las clases dominantes. Williams considera que se trata del "medio de incorporación práctico más poderoso", pues concierne a un "proceso deliberadamente selectivo y conectivo que ofrece una ratificación cultural e bistórica de un orden contemporáneo"27, que "naturaliza" el orden establecido, perpetua su dominación e impide observar claramente el recorte intencional del pasado que supone.

Lo que se trata de expresar es que la utilización desprevenida del concepto de tradición, puede generar confusiones y contradicciones difíciles de resolver. Éste, como cualquier otro, es un concepto que debe ser dimensionado como resultado de una lucha por su sentido, en un momento y lugar determinados, y no como una definición estática, aplicable indistintamente en cualquier caso.

De esta manera, lograremos apreciar cómo la apelación a la tradición puede significar -en determinadas circunstancias- una resistencia legítima 
de un sujeto que afirma valores propios ante la imposición de formas de vida, de prácticas y visiones que poco tienen que ver con los intereses que defienden las clases subalternas, o que, incluso, colisionan con ellos. Un ejemplo de ello es el que referimos anteriormente, cuando abordamos el tema de la resistencia desde el campo de la cultura popular ante el avance capitalista en Europa, a partir del siglo XVI. Es decir, que ciertas formas de comprender el mundo y actuar sobre él, puestas en marcha por los sectores subalternos de la sociedad europea, se enfrentan con las modificaciones que impulsan los sectores dominantes - acorde a sus intereses y proyectos-.

Muchas veces, será en el ámbito de las costumbres y las prácticas comunes, donde el avance capitalista encontrará resistencias tanto o más profundas que en el ámbito económico o institucional.

Esto no implica afirmar en modo alguno que las costumbres populares fueran $\rightarrow$ sean- "buenas" o "puras" por sí mismas. Es necesario destacar que, al igual que otros ámbitos, son resultado de luchas, contradicciones, imposiciones, relecturas, etc., donde no faltan rasgos claramente impuestos por los sectores dominantes. Sin embargo, cierto sentido comunitario, desarrollado previamente a la etapa capitalista, caracterizado por la "ausencia" del interés de acumulación (propia del capitalismo) y la inexistencia de conceptos como Estado, Nación o soberanía, condicionaron la manera de percibir las características del nuevo sistema que se estaba conformando y que venía a barrer con aquella organización. La manera en que se manifestaba esta "economía moral de la plebe, por su resistencia a la economía política de mercado"28, difería según los casos. Podemos observar acciones directas para condenar una actitud adúltera (engaño, divorcio, etc.) o denunciar el abuso de los nacientes intermediarios comerciales (especulación, aumentos encubiertos, etc.). Es decir que, tanto en el ámbito privado como público, la muchedumbre se veía obligada a expresar su disconformidad ante el debilitamiento de las formas establecidas.

Es por ello que nos permitimos diferir con aquellas posiciones que únicamente ven en las expresiones de la cultura popular una resistencia moral frente a la devaluación de la solidaridad ${ }^{29}$. En este sentido es interesante la postura de Grignon y Passeron cuando insisten en la imposibilidad de buscar "en todas las formas de expresión reactivas engendradas por la denegación del dominante —dado que su contenido cultural es ordenado mecánicamente por un proyecto de rechazo 
ideológico a la dominación simbólica- el paradigma de la capacidad popular a la autonomía simbólica. Cuando el concepto de фresistencia cultural' termina por revestir todas las acciones populares no reductibles a la sumisión, se convierte en mutilación y censura de la descripción"30.

En ciertas ocasiones, existen reacciones ideológicas mediante las cuales los grupos dominados - a falta de otras armas culturales y ante la ausencia de toda posibilidad de rebelión real- logran hacer de la dominación sufrida un objeto simbólico distanciado y domesticado a la vez por la irrisión, el humor agresivo, la jactancia revanchista o, también, la idealización ética o sentimental de su posición: refranes de presidarios o de galeotes, cantos de esclavos, canciones de campaña, endechas que evocan hechos célebres de los que están fuera de la ley, canciones llorosas sobre las desgracias de los pobres, etc. ${ }^{31}$.

Incluso, la imposibilidad de vislumbrar la función integradora, en la que pueden llegar a derivar aquellas expresiones culturales de supuesta "resistencia" de los sectores dominados o subalternos, podría obturar el análisis del mecanismo que hace que dicha resistencia sea la que más conviene al sector dominante. Esto sucede por ejemplo, cuando la resistencia desde las expresiones populares "cumple una función ideológica de revigorización de la moral de los dominantes por medio de pequeñas ¿victorias morales' compensatorias con las que tomaba revancha y se contentaba (el dominado) ${ }^{\text {"32 }}$.

De lo que se trata, es de no desconocer los límites existentes en ciertas formas de expresión, al caer en posiciones simplistas que sólo ven en ellas gérmenes de futuras rebeliones. Si bien, algunos aspectos de la cultura popular tienen la capacidad de servir como herramienta de transformación, también debemos reconocer que ciertas expresiones de aparente rebeldía, son aceptadas, permitidas y hasta pautadas por las clases dominantes, quienes encuentran en ellas formas no políticas de descomprimir situaciones conflictivas. A su vez, sirven de placebo a los sectores subalternos, quienes durante un tiempo limitado "juegan" a la rebelión.

De todas maneras esta salvedad no debería impedirnos observar que ciertamente existen numerosas manifestaciones tendientes a reforzar el carácter comunitario de ciertos aspectos de la vida del pueblo y que pueden significar verdaderas oposiciones a los sectores dominantes. No intentamos una imposible e ilusoria vuelta a las visiones sociales características de las etapas precapitalistas; sin embargo, (re)tomar contacto con necesidades,

Costumbre y tiodiclón: la cultura popule entre la rebeldia y el consenvadurismo 
experiencias y miradas anteriores, puede servir como guía a la hora de un análisis crítico que permita problematizar los valores y creencias que se han impuesto y naturalizado.

Podemos asegurar, que en un contexto en el que se producen transformaciones estructurales que implican la ruptura de pautas y valores arraigados en la sociedad -tal el caso del avance capitalista en Europa-, la apelación a la tradición, surge como herramienta de resistencia y reafirmación comunitaria, destacándose en este caso, valores como la solidaridad, el desinterés material y el bien común. Se produce un rescate de costumbres tradicionales (más allá de su justeza) que impiden -al menos por un tiempo- el control total por parte de la nueva clase dominante.

A pesar de esto, en otro contexto, la tradición puede ser un elemento fundamental de las clases dominantes, en su lucha por mantener la hegemonía. Serán útiles aquí, las consideraciones de Williams para comprender esta variante del concepto tradición $n^{33}$.

El autor considera la tradición como una fuerza activamente configurativa - aunque aclara que no significa que se trate simplemente de un complejo de rasgos y elementos dominantes, ya que es siempre una interconexión-, debido a que en la práctica la tradición es la expresión más evidente de las presiones y límites dominantes y hegemónicos. Es decir que cumple funciones como el medio de incorporación práctico más poderoso, al presentar su versión intencionalmente selectiva de un pasado configurativo y de un presente preconfigurado, que resulta entonces poderosamente operativo dentro del proceso de definición e identificación cultural y social ${ }^{34}$.

Aparece aquí la versión de tradición en manos de los sectores dominantes, que es funcional a sus intereses. La misma consiste en la creación, rescate o recorte de ciertas formas, costumbres, prácticas, historias y valores que explican y justifican su posición dominante y limitan la acción transformadora o cuestionadora de otros sectores, al ofrecer una ratificación cultural e histórica de un orden contemporáneo.

En este caso, la tradición sería el vehículo central de "comunicación de una doctrina" específica, acorde a las necesidades de las clases dominantes, aunque presentada como universal y "sagrada", lo que dificulta su problematización y coloca a sus críticos -en muchos casos- por fuera de la sociedad y los valores ancestrales, ante la aparente imposibilidad 
de rebatir argumentos basados en elementos que vienen del pasado -por esto inamovibles-y explican el presente - -supuestamente determinado-.

Sin embargo, la pretendida homogeneidad que presenta esta versión de la tradición, puede ser reconfigurada a partir de nuevas lecturas de ese pasado o del rescate de aspectos dejados de lado por las clases dominantes. Si bien esta opción aparece como una tarea de difícil realización, por otro lado es la misma "táctica" utilizada por los sectores hegemónicos. De esta manera se explicaría la posibilidad de transformar un elemento servil a los intereses dominantes, en un punto de resistencia de las clases dominadas, a partir de la crítica, problematización, reelaboración y rescate de elementos tradicionales del pasado que sean útiles a estos sectores. $\mathrm{Al}$ decir de Williams la tradición es al mismo tiempo "poderosa y vulnerable". Poderosa, porque se halla sumamente capacitada para producir conexiones activas y selectivas, dejando de lado otras por "sin precedentes" o "extranjeras". Vulnerable, porque el verdadero registro es efectivamente recuperable y gran parte de las continuidades prácticas alternativas o en oposición todavía son aprovechables ${ }^{35}$.

Será útil aquí, traer a colación los conceptos de residual y activamente residual, desarrollados por Williams ${ }^{36}$, a efectos de enriquecer la problemática de la tradición.

$\mathrm{Al}$ hablar de "residual", el autor hace referencia a aquello que "ha sido formado efectivamente en el pasado, pero todavía se halla en actividad dentro del proceso cultural; no sólo -y muy a menudo ni eso- como un elemento del pasado, sino como un efectivo elemento del presente. Por lo tanto, ciertas experiencias, significados y valores que no pueden ser expresados o sustancialmente verificados en términos de la cultura dominante, son, no obstante, vividos y practicados sobre la base de un remanente -cultural tanto como social- de alguna formación o institución social y cultural anterior" ${ }^{37}$.

Nos encontramos aquí, a nuestro entender, ante aquellas manifestaciones culturales y sociales - propias de etapas anteriores- que se mantienen vigentes a pesar de cambios estructurales que transformaron el contexto en el que surgieron, se desarrollaron y desde donde eran explicadas.

Si bien resulta complicado establecer en qué momento una expresión o práctica deja de ser "contemporánea" y se vuelve "residual", sí creemos posible encontrar en numerosos aspectos de la tradición, elementos residuales.

Costumbre y hacictón: la cultura popular entre la rebeldia y el conservacturismo 
Pero tal vez lo más interesante a los fines de nuestro estudio sea que para Williams lo residual, "puede, a diferencia de lo arcaico ${ }^{38}$, presentar una relación alternativa e incluso de oposición con respecto a la cultura dominante"39.

De alguna manera, lo residual, en su afán de persistencia, tiene la capacidad de enfrentar lo dominante. Esto podría ayudar a comprender aquellas manifestaciones "tradicionales" practicadas por los sectores subalternos -que se oponen a las nuevas estructuras- en una dimensión más compleja que lo simplemente "conservador".

De todas formas vale aclarar, que no toda apelación a valores o prácticas tradicionales que aparecen como residuales, es en sí misma opuesta al orden dominante. En este sentido cabe diferenciar entre lo residual que es parte de la lógica dominante (o que ha sido incorporado) y lo que ciertamente se le opone como alternativa, que podríamos denominar como activamente residual.

Lo activamente residual no sólo interesa a los sectores subalternos que lo practican, sino que es materia de preocupación de las clases dominantes, quienes intentarán (y en varias ocasiones lograrán) incorporarlo - “a través de la reinterpretación, la disolución, la proyección, la inclusión y la exclusión discriminada"40 - para resignificarlo a la medida de sus intereses. Así, podemos asegurar que es en lo activamente residual donde se encuentran los elementos que pueden llegar a conformar una alternativa cierta al orden dominante. Por esto mismo, la incorporación y domesticación de dichos elementos puede ser más peligrosa para los sectores dominados que las propias herramientas que habitualmente utilizan los sectores hegemónicos, al presentarse como alternativa de oposición eficaz y probada en casos concretos, aunque ahora cumpla funciones diametralmente opuesta.

En su obra Costumbres en común, E. Thompson, relata como ciertas festividades y creencias populares de la Edad Media, fueron incorporadas por la Iglesia al calendario religioso como forma de cristianizar y servir de refuerzo a la autoridad de clerical. Sin embargo, con el paso del tiempo y el debilitamiento de la autoridad de la Iglesia, muchas de estas prácticas volvieron a ser propias de la plebe y adquirieron nuevamente un carácter secular $^{41}$. Si bien, no estamos asegurando que de por sí estas fiestas hayan tenido un carácter opositor a los sectores dominantes -más allá del potencial cuestionador que supone toda práctica que no se amolda enteramente a las formas impuestas- el ejemplo sirve para comprender que la lucha por el sentido es constante y nunca definitiva. 
El rescate o la supervivencia de elementos residuales (formas, prácticas y valores del pasado), puede entonces, tener diferentes características según quiénes sean sus ejecutores. Los sectores dominantes intentarán justificar su hegemonía a partir de una tradición selectiva que "desemboca naturalmente" en el orden establecido. Los sectores subalternos, se aferrarán a la tradición, como manera de resistir la dominación y pueden -a partir de rescatar aspectos diferentes o resignificar el pasadoconvertirse en sujeto de oposición y transformación.

En todo caso, tanto las clases subalternas como las dominantes llevan la lucha de clases al terreno de la tradición -en el caso de lo activamente residual esto es bastante claro-, enfrentando modelos y recortes diferenciados de un pasado "común". Por lo tanto, lo que debería analizarse es el resultado de esa lucha en un momento determinado y no un concepto "estático" y ahistórico, que impida el análisis profundo en nombre de la "cientificidad".

\section{Conclusión}

La posibilidad de dimensionar los procesos sociales -expresiones políticas, manifestaciones públicas, formas de resolución de conflictos, etc.- que involucran a los sectores subalternos de una sociedad, depende en gran medida de nuestra capacidad crítica a la hora de abordar los ejes centrales necesarios para su comprensión: cultura, costumbre, tradición, pueblo, popular. Considerar estos conceptos históricamente -en oposición a definiciones estáticas donde deben "encajar" los fenómenos que investigamos - será un primer paso para una comprensión más completa de los mismos. De igual modo, la infructuosa tendencia a valorar como "positivos" o "negativos" en sí mismos, la utilización o simple apelación a ideas del pasado por parte del pueblo, surge como uno de los principales límites autoimpuestos por la investigación social.

De esta manera, podrán problematizarse nociones como las de tradición o costumbre, y ver en ellas, algo más que automáticas repeticiones de las imposiciones de las clases dominantes, o por el contrario, que expresiones puras e incontaminadas "propias del pueblo" ( $y$ por tanto beneficiosas para el mismo)

Reafirmamos la idea de que la tradición no es ni "buena" ni "mala", sino que es un escenario más (tal vez uno de los más importantes) de lucha por el sentido. Por lo mismo, no encontraremos prácticas o creencias tradicionales "puras" o que únicamente se correspondan con los intereses de un sector de la sociedad, sino que será conveniente observarla como el 
resultado de una lucha entre actores sociales con intereses diferentes, por lo que podremos encontrar ciertos aspectos o lecturas que sirvan a cada uno de estos sectores. Remarcamos que se trata de una lucha - con etapas, intensidad y divergentes formas de resolución - y no de una amistosa negociación entre partes; por tanto, es necesario analizar las ventajas y capacidades que los sectores enfrentados poseen.

Aceptar esto, ayudará a no caer en análisis simplificados al extremo de no poder observar en la apelación a la tradición - por parte de las clases subalternas - otra cosa más que su aparente tendencia al conservadurismo. Por este camino, las formas de resistencia que se basan en valores y prácticas tradicionales y desde donde pueden surgir visiones críticas que trasciendan la mera protesta, quedarían obstruidas para el análisis. Del mismo modo, no tener en cuenta el recorte intencionado que de la tradición realizan los sectores dominantes, e igualar tradición con conservadurismo, impediría resaltar la posibilidad de cuestionar esa selección y/o de realizar una que rescate otros elementos con capacidad de oponer una alternativa.

Otro tanto ocurre cuando nos introducimos en el ámbito de las costumbres. Remarcamos la idea de campo como espacio de cambio y enfrentamiento, en el que actores sociales concretos luchan por sus intereses y logran, en mayor o menor medida, imponerlos. Esto último, apuntala la idea de escenario dinámico y variable, que lejos de responder a los designios de una única clase que impondría su voluntad de una vez y para siempre, es resultado de las luchas constantes. Así comprenderemos cómo algunos designios de las clases dominantes de una época pasada, sirven de herramienta de resistencia para las clases populares que se enfrentan a las nuevas clases dominantes. Aunque no debemos desconocer las (des)ventajas ni las (in)capacidades de cada sector, la posibilidad de relectura de las costumbres es permanente para cualquiera de los sectores enfrentados. Allí reside su riqueza, a la hora del análisis.

De esta manera, hemos aspirado a profundizar un aspecto central a la hora de comprender los cambios, resistencias, avances y retrocesos producidos en la lucha entre clases, que se lleva a cabo en los distintos ámbitos de la vida en sociedad y que, por diversos motivos, no son siempre dimensionados. Una aproximación - desde una mirada crítica- a los fenómenos y las expresiones sociales que afectan a las clases subalternas, permitirá profundizar cuestiones fundamentales a la hora de comprender una sociedad que se transforma al calor de las luchas entre sujetos sociales. 


\section{BIBLIOGRAFÍA}

Altamirano, Carlos (Dir.). Términos críticos de sociología de la cultura, Paidós, Buenos Aires, 2002.

Buchrucker, C. y otros. El mundo contemporáneo: historia y problemas, Crítica, Barcelona, 2001.

Fernández Nadal, Estela. Revolución y utopia; Francisco de Miranda y la independencia bispanoamericana, EDIUNC, Mendoza, 2001.

Grignon, Claude y Passeron, J. Claude. Lo culto y lo popular: miserabilismo $y$ populismo en sociología y en literatura, Nueva Visión, Buenos Aires, 1991.

Samuel Raphael (ed.), Historia popular y teoria socialista, Crítica, Barcelona, 1981.

Thompson, E. Costumbres en común, Crítica, Barcelona, 1995.

Thompson, E. Tradición, revuelta y conciencia de clase, Crítica, Barcelona, 1984.

Williams, Raymond. Palabras Clave un vocabulario de la cultura y la sociedad, Nueva Visión, Buenos Aires, 2000.

Williams, R. Marxismo y Literatura, Península, Barcelona, 1997.

NOTAS

1 Gramsci, A. Cultura y Literatura. Citado en Altamirano, C. Términos críticos de sociología de la cultura, p. 52.

2 Hall, Stuart, "Notas sobre la construcción de To popular", en Samuel, R., Historia popular y teoría socialista, p.103-104.

3 Aróstegui, Julio. “Orígenes y problemas del mundo contemporáneo", en Buchrucker, C. y otros. El mundo contemporáneo: bistoria y problemas, p. 46.

1 Cfr. en Buchrucker, C. Op. cit., p.20-31.

$5 \quad$ Aróstegui, Julio. Op. cit., p. 47.

- Soboul, A. "¿Reforma o revolución? Sobre la función histórica del absolutismo ilustrado". Cit. en Fernández Nadal, Estela. Revolución y utopía; Francisco de Miranda $y$ la independencia bispanoamericana, p.46.

7 Tilly, Charles. Cit. en Buchrucker, C. Op. Cit., p. 55.

$8 \quad$ Giddens, Anthony. Ib idem. p. 55.

9 Thompson, E. Costumbres en común, p.72-73.

10 Hall, Stuart. Op. cit., p. 94.

1 Cit. en Williams, Raymond. Palabras Clave; un vocabulario de la cultura y la sociedad, p.89 
Williams, Raymond, Ibidem, p. 89.

Cirese, Alberto. Cit. en Altamirano, Carlos. Op. Cit, p.48.

Cfr. Thompson, E. Op. Cit., p. 19.

Ginzbourg, C. El queso y los gusenos. Cit. en Altamirano, C. Op. Cit., p.51.

Cfr. Willimas, Raymond. Op. cit., p.73-77.

Thompson, E. Op. cit., p. 19.

Hall, Stuart. Op. cit., p. 94.

Cfr. Thompson, E Op. cit., p.18

Cfr. Ibidem, p. 22

Thompson, E. Tradicion, revuelta y conciencia de clase, p.63.

Ibidem. p. 65.

Ibidem. p. 66.

Cfr. Thompson, $E$. Costumbres en comuin, p.129

Cfr. Ibidem, p 30-38. Thompson llama "sistema paternalista a la práctica de contención social y mediación entre patricios y plebeyos, puesta en marcha por los primeros y que se pierde ante el individualismo competitivo del joven capitalismo.

Thompson, E. Tradición, revuelta y conciencia de clase, p133-134.

Williams, R Marxismo y literatura, p.137-138.

Thompson, E. Cit. en Altamirano, C., Op. cit., p. 51.

De Certeau, M. Cit. Ibidern, p. 53

Grignon-Passeron. Lo oculto y lo popular: miserabilismo y populismo en sociologia y en literatura, p. 75

Ibidem, p. 75.

Ibidem, p. 77.

Cfr. Willimas, R. Palabras clave, p.319-320 y Marxismo y literature, p.137-150.

Williams, R. Marxismo y literatura, p. 137.

Williams, R. Ibidem, p. 139.

Cfr. Ibidem, p.143-149.

Ibidern, p.144.

Williams define lo arcaico como "lo que se reconoce plenamente como un elemento del pasado para ser observado, para ser examinado o incluso ocasionalmente para ser conscientemente «revivido" de un modo deliberadamente especializado". Ibidem, p.144.

39 Ibidem, p.144.

4o Ibidem, p.145.

41 Thompson, E. Costumbres en común, p. 66-70. 